\title{
NOVOS SONHOS DE VERÃO SEM FIM: SURFE, MULHERES E OUTROS MODOS DE REPRESENTAÇÃO
}

\author{
DR. CLEBER DIAS \\ Doutor em Educação Física na Universidade Estadual de Campinas (Unicamp) \\ Professor Assistente da Faculdade de Educação Física da \\ Universidade Federal de Goiás (UFG) (Goiás - Brasil) \\ e-mail: cag.dias@bol.com.br
}

\begin{abstract}
RESUMO
Este artigo pretende analisar a maneira que o filme Blue Cruch (2002) - no Brasil A onda dos sonhos - captura, representa e difunde sentidos sobre o surfe. O fundamento da iniciativa é o de que filmes como esse, captam o que a prática de esportes simboliza, atribuindo-lhes assim significados que podem ser interpretados a partir deles mesmos. Nesse caso, três elementos do seu enredo foram tomados como eixo de análise: i) o modo de representação da mulher; ii) a crescente comodificação como forma de se relacionar com esta modalidade; iii) a tendência realística-documental dos filmes de surfe. São dimensões que dramatizam dinâmicas culturais desta modalidade, encerrando uma ambivalência que traduz as disputas, clivagens e tensões próprias a qualquer prática cultural.
\end{abstract}

PALAVRAS-CHAVE: Filmes; esportes na natureza; surfe. 
"A beleza do surfe está na coreografia e no talento artístico do surfista de estar paralelo ao cinematógrafo"

John Stockwell

\section{INTRODUÇÃO}

A sociedade contemporânea vive saturada de imagens. Filmes, vídeos, fotografias e anúncios publicitários impregnam o olhar e o mobilizam de maneira específica. Não por acaso, em 1967, Gui Debord (1997, p. 19) se referiu ao mundo contemporâneo como A sociedade do espetáculo, onde, nas suas palavras, "tudo o que era diretamente vivido se afastou numa representação".

Conteúdos e meios de expressão mobilizados por imagens são sempre constituídos por processos sociais mais amplos. Estamos então diante de manifestações produzidas historicamente, construídas socialmente e definidas culturalmente. Isto quer dizer que são também materializações conscientes ou inconscientes de interesses e necessidades dos atores que os produzem. Assim, direta ou indiretamente, expressam e refletem cosmologias, ao mesmo tempo em que criam aspectos da realidade, na medida em que tentam representá-los.

Transferindo esses entendimentos para o campo esportivo, podemos dizer que as imagens produzidas nessa esfera em particular podem servir de suporte para reflexões acerca dos seus significados (a esse respeito ver MELO, 2006). Em outra oportunidade havíamos sugerido já a intenção de tomar produtos culturais desse tipo como veículo para análises dos esportes na natureza, mais especificamente (c.f. DIAS, 2008). Aqui, na tentativa de seguir perseguindo tais ambições, este artigo pretende analisar a maneira que o filme Blue Cruch (2002) - que no Brasil foi comercializado como A onda dos sonhos - tenta capturar, representar e difundir sentidos e significados sobre o surfe. $\bigcirc$ fundamento da iniciativa é o de que filmes dessa natureza tentam, à sua maneira, capturar o que essa prática simboliza, atribuindo-lhe assim significados que podem ser interpretados a partir deles mesmos. Esse entendimento, inclusive, tem motivado muitos pesquisadores a tomarem filmes ou outros produtos culturais ligados ao surfe, como revistas, na intenção de interpretar sociologicamente essas práticas (a título de exemplo ver HENDERSON, 2001; ORMROD, 2005, 2007).

\section{SURFE E FEMINISMO: A HORA E O LUGAR DAS MULHERES}

O filme Blue Crush (2002) conta a história de uma jovem menina havaiana apaixonada pelo surfe. Seu nome é Anne Marie Chadwick, personagem interpretada por Kate Bosworth. Seus sonhos, desejos, projetos e aspirações estão todos 
direcionados a este esporte. E a maneira como o relacionamento dessa jovem com o surfe é retratado na película reflete e deixa entrever uma série de dinâmicas que têm, na realidade, perpassado essa subcultura esportiva nos últimos anos. Mas qual o sonho de Anne Marie e o que ela pretende, de fato, alcançar com e no esporte?

Percebe-se logo no início do filme que Anne Marie está afastada das imagens convencionalmente atribuídas a um surfista. Além do evidente fato de ser mulher, ela não parece ser uma consumidora de drogas, tampouco alguém pouco afeita aos compromissos ou ao decoro comportamental; traços arquetípicos de um surfista no imaginário popular. Ao contrário, ela aparece-nos como uma jovem cujo cotidiano será permeado de disciplina. Acorda cedo, antes mesmo do sol nascer; sai para correr e na volta, enquanto confere as condições meteorológicas pelo telefone, escreve no espelho com batom: "Sete dias para o campeonato. Nada de moleza". Ela alimenta o sonho de vencer o Pipe Masters, uma importante competição de surfe que está prestes a acontecer.

A condição dessa personagem, bem como seus valores ou a maneira como sua concepção de surfe é apresentada nos oferece algumas chaves interpretativas. A primeira, mais óbvia, é sobre a condição da mulher e do surfe feminino. É essa, inclusive, a principal intenção explícita da narrativa. Seu roteiro, assinado por Lizzy Weiss (socióloga especializada em estudos feministas e que já trabalhara na MTV) e John Stockwell (que assumiu também a direção), foi inspirado em Life's Swell, artigo da jornalista Susan Orleam, publicado em 1998 na revista norte-americana Outside (que tem uma versão brasileira chamada Go Outside). $\bigcirc$ artigo fala das meninas surfistas de Mauí; sobre seu cotidiano, quase todo preenchido pelo surfe; suas expectativas, dificuldades e, principalmente, sobre os contrastes produzidos pela dominação masculina na cultura do surfe. "O aquecimento dos homens e dos meninos era narrado através do sistema de som, mas durante o aquecimento das meninas e das mulheres o narrador esteve silencioso" (ORLEAM, 2008).

Nesse sentido, pode-se dizer que o filme é bastante fiel ao texto que lhe inspirou. Já no início, Anne Marie e suas amigas são hostilizadas na chegada à praia por uma gangue de rapazes. Eles as provocam perguntando se já aprenderam a surfar de verdade. Em contrapartida, oferecem "proteção" para que possam surfar algumas das melhores ondas do dia. Essas ajudas e garantias parecem mesmo necessárias. Por causa da qualidade de suas ondas, constantes, grandes e regulares, o Havaí ficou conhecido como a Meca do surfe mundial. O resultado tem sido a presença de um pequeno exército de surfistas nas águas do arquipélago, que disputam furiosamente o direito de deslizarem sobre suas ondas. É o famoso crowd havaiano. Nessas circunstâncias, tem-se estabelecido uma espécie de lei do mais forte, identificado entre eles próprios como localismo (a esse respeito ver DIAS; 
ALVES JUNIOR, 2007, especialmente capítulo 3), onde frequentadores do local definem critérios que determinam quem terá prioridade para a prática do esporte. Às vezes com uso da violência, esses grupos acabam tendo uma espécie de monopólio sobre as ondas, e as mulheres, em geral, não constituem um grupo contemplado por essas arbitrárias regras de uso da natureza.

No filme, as meninas se mostram um pouco assustadas com as condições do mar. "Está da pesada. Perigoso", dizem elas. Preferem então ficar no banco de areia ao invés dos corais, onde as ondas estão maiores e mais perigosas. No entanto, já na água, um dos rapazes volta a Ihes desafiar e chama Anne Marie para o line-up, para a "arena". Ela aceita e o acompanha. Ao chegar, cumprindo a promessa de proteção, ele logo adverte os demais: "Ela está com a rapaziada. Vai pegar umas ondas. Se atrapalharem, vão se ver comigo". Depois de fracassar numa primeira tentativa, a menina se vê prontamente diante de estigmas sexistas: "Pipe não é lugar de mulher. Não é concurso de beleza".

Na sequência, boa parte da trama dilui um pouco a dimensão propriamente esportiva e vai ser ocupada por um romance entre Anne Marie e um turista de férias no Havaí. É uma estrutura narrativa bastante comum aos filmes de surfe ficcionais que, de acordo com as análises de Victor Melo e Rafael Fortes (2009, p. I I7), "se destacam pelo mergulho no universo dos jovens", enfatizando "paixões e turbulência nos relacionamentos amorosos".

Apesar da dinâmica tipicamente hollywoodiana, é a condição mesmo da muIher que está em tela com o filme. A polêmica que a personagem principal tem que enfrentar a partir desse momento diz respeito a se dedicar ao novo relacionamento ou continuar perseguindo suas ambições esportivas, concentrando-se nos treinos ao invés de viver aquele amor. Autonomia e emancipação feminina são questões que emergem nessa relação de Anne Marie. Quando ela descobre que seu parceiro costuma estabelecer relacionamentos efêmeros e casuais durante as férias, Ihe diz que está confusa e pergunta quem ela é afinal e o que deve fazer. A resposta? "Uma mulher que não pergunta aos homens o que deve fazer".

De certo modo, toda a narrativa se orienta para exibir o desafio e as dificuldades enfrentadas pelas mulheres para entrarem no universo do surfe, lugar social marcado por valores de masculinidade. De certa forma, o surfe feminino serve de alegoria para tratar da discriminação às mulheres em determinados espaços sociais. O diretor John Stockwell declara no making off que um dos principais desafios antes mesmo do início da produção era "mostrar ao estúdio do que as mulheres eram capazes e como era um esporte visual e interessante".

Não decorre daí que seu enredo seja plena e absolutamente marcado por uma coloração crítica no que toca ao papel das mulheres no esporte ou mesmo na 
sociedade de modo mais geral. Ao contrário, nota-se, em muitos momentos, uma oscilação entre a reprodução de preconceitos machistas e a exaltação das capacidades femininas. Em uma das cenas do filme, o narrador da competição faz comentários bastante duvidosos aos implícitos propósitos feministas da história. Referindo-se à adversária de Anne Maria, diz-se que "Ela tem muita coragem. Ela surfa como um homem". É a performance masculina, nesse caso, que é tomada como parâmetro e como modelo ideal. Por outro lado, em outra cena, já no fim do filme, depois de cair perigosamente de uma onda durante as competições do Pipe Masters, Anne Marie decide seguir na disputa. Quando interpelada por uma de suas amigas sobre o porquê de fazer aquilo, diz que o fará em nome de um ideal, além dos possíveis interesses mais imediatos e individuais: o de mostrar que as mulheres podem ser tão boas quanto os homens.

Saber se a reivindicação das mulheres deve se orientar no sentido de buscarem assemelhar-se com os homens ou afirmarem suas possíveis peculiaridades é um debate em aberto no seio do próprio movimento feminista. De todo modo, as surfistas profissionais que participaram das gravações declaram ver no filme uma oportunidade para "conscientizar as pessoas sobre o surfe feminino".

O diagnóstico é relativamente justo. A prática do surfe entre as mulheres tem crescido consideravelmente nos últimos anos. De acordo com Douglas Booth (200 I), na Austrália, onde a modalidade experimenta grande popularidade, estimase que aproximadamente I/3 dos dois milhões de surfistas do país sejam mulheres. Nos Estados Unidos, os balanços dos meados dos anos 1990 apontavam para uma constituição percentual de cinco por cento do público feminino entre a população total de surfistas do país. No fim da década, esse número já era de surpreendentes cinquenta por cento.

De início, dois aspectos podem ser apontados como catalisadores do aumento do envolvimento das mulheres com esse esporte: o desenvolvimento da sua esfera competitiva e o re-ordenamento dos seus modos de retratação pela mídia.

Até meados de 1960, as mulheres se fizeram presente de maneira mais ou menos equitativa nesse universo esportivo. Depois disso, no entanto, testemunhou-se uma progressiva marginalização. $\bigcirc$ estabelecimento de novas concepções concorreu para a consolidação de uma abordagem técnica das ondas que privilegiava a competição, a força e a agressividade em detrimento da leveza ou da plasticidade, aspectos que predominaram outrora. Assim, virilidade e coragem tornaram-se os principais meios pelos quais surfistas angariavam prestígio e respeito da própria comunidade. E na esteira das definições de identidade convencionalmente atribuídas aos homens e às mulheres, esses eram traços tipicamente masculinos. Logo, a prática do surfe vai tornando-se um lugar social pouco recomendável à presença de mulheres. 
Na segunda metade da década de 1990, contudo, algumas condições convergiram para tornar possível o prenúncio de mudanças desse quadro. Em primeiro lugar, surfistas mulheres alcançam performances competitivas admiráveis e ganharam notabilidade pública por causa disso, como é o caso de Lisa Andersen - talvez o exemplo mais ilustrativo. Andersen ganhou quatro títulos mundiais consecutivos entre 1994 e 1997, atraindo atenção para o surfe feminino. Seu estilo de surfar encarnava alguma medida de desprezo pela antiga e valorizada graciosidade das mulheres sobre as pranchas, que fora a marca do surfe feminino por muito tempo, voltando-se, ao invés disso, para performances mais atléticas, no que era acompanhada por outras competidoras. Ao mesmo tempo, esse grupo de atletas se negava a apelar ao uso e a exploração dos seus atributos de beleza como ferramenta de mercado, isto é, para obtenção de patrocínios ou publicidade. $\bigcirc$ resultado foi a formação de toda uma geração que "pôs abaixo sua sexualidade e feminilidade e enfatizou sua capacidade atlética ostentando habilidades" (BOOTH, 200 I, p. I I).'

Em segundo lugar, e de outra forma, medidas administrativas reformularam nessa mesma época o modo de organização das competições femininas. A Associação de Surfistas Profissionais criou um comitê específico para coordenar as provas das mulheres, com novos cargos dirigentes para ajudar a organização e promoção dos eventos. Reduziram-se também o número de etapas e de participantes do circuito feminino, intensificando o nível das competições. Um dos resultados foi o incremento comercial do segmento, surgindo até mesmo um ramo de negócios especializados em produtos para o surfe feminino. ${ }^{2}$

De maneira mais geral, e em alguma medida pelo menos, o filme Blue Crush é um produto desses processos.

\section{MÍDIA E COMODIFICAÇÃO}

O segundo aspecto do filme que poderíamos destacar diz respeito à comodificação do surfe. Para Anne Marie, a onda dos sonhos já não é exatamente aquela que fora apresentada para algumas gerações anteriores. Se em Endless Summer,

I. Mais recentemente, quase como dividendo dessas dinâmicas, veremos o modo de retratação que a imprensa esportiva edifica em torno da Maya Gabeira. Em uma enquete organizada em 2007 pelo Radicais, coluna semanal do jornal $\bigcirc$ Globo especializada em esportes radicais, a surfista foi eleita pelos leitores como "o destaque radical do ano".

2. No Brasil, o recente aumento do interesse feminino por este esporte tem movimentado sua indústria. Segundo uma reportagem da revista Isto é, publicada em fevereiro de 2009 e referindo-se exatamente a esse processo, as meninas, "com pranchas coloridas e femininas, estão invadindo as praias e movimentando a indústria do esporte" (SGARBI, 2009). 
por exemplo, filme de 1964, o projeto de felicidade apresentado para um surfista era viver uma vida sem compromissos, descobrindo e explorando novos lugares; em Blue Crush, ao contrário, o ideal que aparece é o da profissionalização. Em vários momentos, esse é um desejo que vem à tona bem abertamente. Quando as meninas vêem uma surfista profissional em um posto de gasolina, uma delas se apressa em dizer, aconselhando Anne Marie:

É a Keila Kenelly. Ela que aproveita a vida. Ela é patrocinada pela Billabong. Que vida. Ela ganha tudo que fotografa para a revista. Cinco mil toda vez que sai na capa. Ganha roupas, pranchas, relógios, óculos de sol. Ela nem precisa abrir a carteira. Se pegar uma boa onda no Pipe Masters será patrocinada como ela. Vai rodar o mundo inteiro. Surf Indo, Austrália, Taiti e por aí vai. Surfar o mundo, baby. Será paga para surfar em ondas livres, perfeitas. Basta você ser notada.

Existe um tom claramente consumista nessas palavras, que afasta bastante a ideia de que o surfe é uma prática desinteressada, gratuita, "alternativa". Ao invés disso, destaca-se a possibilidade do dinheiro, das roupas, das pranchas, dos relógios e dos óculos de sol. E a materialização disso tudo passa apenas pela "necessidade de ser notado". Mas ser notado nesse caso implica o quê exatamente, ou, em outras palavras, ser notado por quem, mais especificamente?

No início das competições do Pipe Masters a voz do narrador oferece-nos uma resposta: "A mídia está aqui em peso. Todo patrocinador, olheiro, buscando a nova sensação do surfe. Pegue uma boa onda e você ficará famoso". É a indústria do surfe, portanto, com toda sua aparelhagem comunicativa que deve ser convencida acerca do potencial e da habilidade dos surfistas.

A noção de que a mídia tem se constituído no mundo contemporâneo como uma esfera de consagração é particularmente verdadeira para o surfe. Temos aí uma prática social cujos critérios de legitimação, senão criados por esses veículos, tem, no mínimo, sido difundidos e multiplicados em larga escala por eles. Não que haja uma espécie de controle absoluto. A questão é que a mídia, nesse caso, tem funcionado como um agente amplificador, reforçando e dando visibilidade a um determinado conjunto de cosmologias que, até por isso, vêm se tornando cada vez mais hegemônicos no âmbito desse esporte. As revistas de surfe, por exemplo, conforme argumenta Leanne Stedman ( 1997, p. 76), podem representar ou expressar a atitude coletiva bem como criá-los. "Assim o processo de seleção editorial nas revistas de surfe não é uma distorção da 'realidade' mas a criação dela".

A maneira como muitos surfistas se socializam nesse esporte tem passado - ao menos desde a metade da década de 1970 - pelo crivo dos seus canais midiáticos especializados, especialmente filmes e revistas. Kelly Slater (2004, p. 104) relata em 
sua autobiografia que "Revistas, vídeos e viagens me apresentaram um mundo de estilos de surfe diferentes [...] Ver Martin Potter mandando um aerial explosivo na capa da revista Surfing, em 1984, quando eu tinha doze anos, mudou minha vida". Da mesma forma, quando liderou um Clube de Surfe na Flórida, ainda no início da adolescência, afirma que realizava junto com os amigos reuniões semanais em que, "na maioria do tempo, ficávamos sentados, lendo revistas de surfe e, às vezes, assistíamos a vídeos" (SLATER, 2004, p. 108).

Os discursos e as narrativas dos filmes e revistas de surfe então prescrevem uma norma sobre as maneiras de conceber e se relacionar com esse esporte. E é justamente uma dessas normas que está em evidência no comportamento da personagem principal de Blue Crush. Na celebração inconsciente de Anne Marie às esferas competitivas e profissionais do surfe - em detrimento as suas dimensões mais recreativas ou informais - está toda uma escala de valores que vêm se impondo ao universo do surfe nas últimas quatro décadas.

Apesar da personagem já ter declarado que sua principal motivação para estar em um campeonato era um possível ideal feminista, nota-se também que a personagem é movida por uma vontade de se tornar famosa e bem sucedida em termos comerciais. Em uma das últimas cenas, talvez a mais definitiva de todo o filme, Anne Marie não consegue um desempenho satisfatório durante a segunda bateria da competição. Três anos antes ela havia abandonado o circuito depois de quase ter se afogado durante uma competição naquela mesma praia. Parece não ter se recuperado do trauma. As más lembranças do episódio atormentam-na ainda. Ela está temerosa e hesitante. Sua adversária, no entanto, deixa a disputa de lado e resolve incentivá-la. Anne Marie então empreende uma tentativa, mas não obtêm sucesso. Cai nas pedras, mas ao menos está bem. Se não serve para ajudá-la na competição, o episódio serve para exorcizar seus fantasmas. Ela parece agora mais segura e confiante. Emerge da água, dispensa ajuda do salva-vidas e volta ao line-up com decisão. Restam apenas dois minutos para o fim da bateria... No horizonte se forma uma ondulação. "É a melhor série do dia", anuncia o narrador. É a última chance de Anne Marie, que não parece disposta a desperdiçá-la. Ela entra na onda e a platéia na praia se mostra, primeiro, apreensiva, depois entusiasmada. Os juízes não têm dúvida: nota dez por unanimidade. De pé sobre a prancha, com a onda explodindo atrás, Anne Marie comemora erguendo os braços. A montagem é canhestra e lembra as produções hollywoodianas sobre o surfe dos anos 50. Mas o veredicto do locutor é retumbante; dissipa o constrangimento e nos ajuda a entender: "Palavras não explicam. Pegar uma onda assim, com toda a comunidade surfista assistindo..."

A excelente manobra não será suficiente para dar-lhe a vitória. Mas não importa mais, ela já é uma vencedora. Seu grande sonho está prestes a se realizar. 
Ao chegar à areia é logo cercada. São fotógrafos, cinegrafistas e fãs. Pedem-lhe autógrafos, pedem-Ihe poses, até que finalmente é interpelada: "Com licença, Anne Marie. Sou Jéssica, da Billabong. Queria ver se você quer trabalhar com a gente". Ela será uma atleta patrocinada finalmente. É o reconhecimento definitivo do seu valor como surfista. Na sequência, veremos a capa da revista Surfing noticiando: "Garotas dominam Pipe. Anne Marie Chadwick, A Nova Garota Billabong".

Temos aí a expressão de um conjunto de transformações que vem se manifestando na cultura surfe: a individualização com o progressivo destaque a personagens individuais, ao invés da identificação coletiva com a comunidade como um todo; a ênfase na competição e finalmente a colonização do esporte por empresas. Stedman ( 1997 ) ressalta que todas essas transformações se exprimem de maneira particularmente aguda na produção cinematográfica sobre o esporte. Nas suas palavras, "o processo pode ser seguido através de uma análise dos filmes de surfe" (STEDMAN, 1997, p. 78). Segundo a autora ainda, as produções anteriores aos anos 1970 tendiam a apresentar os seus personagens como símbolos representativos de todos os surfistas, isto é, de toda a cultura do qual eles eram os portadores. De maneira emblemática, tais personagens não eram sequer nomeados nos créditos dos filmes ou nos materiais promocionais. Depois disso, no entanto, vê-se o foco de atenção ir se dirigindo para performances individuais com entusiasmo pelas competições de surfe. É o processo que Stedman chama de "criação de surf stars".

A carreira de alguns astros o surfe como Kelly Slater foram reconhecidamente influenciadas por filmes assim, produzidos por empresas fabricantes de produtos para esse esporte e centrados sobre um único indivíduo; geralmente o surfista profissional patrocinado pela própria empresa. É o caso de Kelly Slater: in Black and White, vídeo promocional produzido pela Quicksilver para divulgar a celebração do contrato dessa marca com o atleta. Foi o vídeo da empresa mais vendido de todos os tempos e, segundo o próprio Slater, o filme "fez muito mais pela minha carreira do que percebi na época. Até então, muitas pessoas ainda não tinham me visto surfar" (SLATER, 2004, p. 131).

Reportando-se especificamente às produções nacionais, a análise de Melo e Fortes (2009) permite perceber que os filmes brasileiros de surfe também se encaminharam nessa direção. Diferente do que acontecia em filmes como Menino do Rio, de 1981, que retratava o lúdico cotidiano de um surfista e praticante de asa delta, narrativas mais recentes como Fábio Fabuloso, de 2004, representam a esfera competitiva do surfe, destacando a vida nos campeonatos, as conquistas e premiações. Seus protagonistas, ao invés de jovens que simplesmente adotam o esporte como um costume de lazer, passam a ser os profissionais, "que vestem e usam produtos de marcas" (MELO; FORTES,2009, p. I I7). No mesmo sentido, como 
observam os autores, a maioria dessas produções mais contemporâneas recebeu apoio ou patrocínio de empresas ligadas ao surfe ou ao público jovem de maneira geral. Blue Crush, nesse contexto, continua sendo apenas mais um representante bastante paradigmático de todas essas dinamizações.

\section{FICÇÃO REALISTA}

Outro aspecto a ser mencionado aqui é o da intenção de dotar o filme com um forte sentido de realismo. Rochele Balland, Kate Skaurratt e todas as surfistas profissionais que figuram no elenco do filme são personagens da vida real interpretadas por elas mesmas. Do mesmo modo, moradores do local foram recrutados para participar, sempre a fim de acentuar ainda mais esse traço realístico.

Toda a história foi filmada no Nort Shore e imagens do cotidiano das praias capturadas durante a produção do filme foram incorporadas à história, como é o caso de uma em que aparece Tom Caroll saindo da água com o supercílio sangrando. $O$ campeonato em torno do qual gravita toda a narrativa existe na realidade, de modo que poderíamos dizer, em suma, que se trata de uma ficção fortemente perpassada por muitos elementos de realidade.

Um dos produtores, Brian Grazer, que se diz surfista, declarou no making off que pretendia desde o início fazer um filme "que os surfistas achassem o máximo". Planejavam mesmo, nas suas palavras, um "filme autêntico", capaz de expressar todo o estilo de vida surfe. "Queriam cru e real", conforme declara também no making off a surfista profissional Rochele Balland. A ideia, enfim, era representar com a maior fidelidade possível as dinâmicas internas à cultura surfe, tentando com isso angariar credibilidade junto aos praticantes e simpatizantes que, a bem da verdade, constituem o principal público potencial para filmes dessa natureza. Parte da estratégia para alcançar esse objetivo foi dar-lhe essa veia realista.

A grande maioria dos recentes filmes de surfe encerra essa característica, mesmo quando ficcionais, como é o caso de Blue Crush. $O$ fato da história da difusão mundial do surfe ter passado pelo crivo de seus discursos imagéticos ajuda a entender tal caracterização.

Produções como essa têm servido, desde os anos 60, como recurso simbólico e informacional para a constituição de uma comunidade imaginária ao redor dessa prática. Desse modo, constituiu-se uma tradição estética muito comprometida com a ideia de transmitir a realidade e a "essência" desse esporte. Filmes, revistas ou quaisquer outros aparatos comunicativos associados ao surfe deveriam, assim, servir a um propósito pedagógico: o de apresentar, de maneira mais didática e generalizada possível, um costume esportivo inicialmente incompreensível e que 
durante algum tempo esteve restrito a um pequeno gueto marcado pelo estereótipo da marginalidade.

O mass mídia, nesse sentido, apreende, decodifica, amplifica e reforça um determinado perfil para a prática do surfe, induzindo, de certo modo, mais e mais pessoas a procurálo como um canal de realização dos seus desejos. Dito de outro modo, essa complexa cadeia que é a indústria do entretenimento vai oferecer a um público global um modelo de prática e comportamento, estabelecendo pontos de referência para a ação, para o discurso e para a ética de uma massa concentrada de consumidores em potencial. É desse modo que revistas, filmes, propagandas ou programas televisivos funcionarão como um estímulo reforçado na construção de formas de acesso e consumo dessas atividades (AMARAL; DIAS, 2008, p. 9).

A presença de praticantes à frente de produções desse tipo ampliou tais possibilidades. São cineastas ou produtores que se apresentam como entusiastas do esporte e que, até por isso, comungam ou simpatizam com uma parte da sua escala de valores, mobilizando-se então para sua divulgação. Ao longo da década de 1950, a consolidação da praia de Malibu, na Califórnia, como um dos endereços preferidos por produtores e cineastas de Hollywood, favoreceu as ligações do cinema com a cultura surfe, que nessa época também fervilhava justamente naquele parte da orla californiana. Filmes, portanto, constituíram-se como uma estratégia e um recurso potencial - muito bem utilizado por sinal - para a apresentação massiva do esporte. Por isso esses produtos culturais "têm sido um ingrediente crítico nesta cultura" (BOOTH, 1996, p. 313).

Provavelmente em razão desses condicionantes históricos, filmes ficcionais cederam lugar de maneira quase absoluta nos últimos anos a documentários, que podem cumprir de maneira bem mais direta e explícita suas funções explicativas.

\section{CONSIDERAÇÕES FINAIS}

Há alguns anos já se acompanha no mundo surfe uma clara polarização de opiniões quanto aos sentidos mais profundos que a prática desse esporte poderia trazer consigo. De um lado, os que se dizem "mais pé no chão", com uma interpretação que se quer mais realista e objetiva. É o caso, por exemplo, de Marcelo Serpa, surfista e publicitário que criou campanhas de sucesso explorando as associações simbólicas desse esporte. Trata-se de alguém que "acredita no surf como esporte mainstream na publicidade de agora em diante" (FLUIR, 2006). De outro lado, aqueles que se pretendem portadores do "verdadeiro espírito do surfe", noção bastante vaga que alude a uma sensibilidade mais romântica em contraste a um racionalismo mais instrumental, valorizando a espiritualidade ao invés do materialismo; 
o ócio em detrimento do negócio. A lista de exemplos desses últimos casos parece sensivelmente maior.

No limite, cada uma dessas posições tem em comum sua admirável inocência além, é claro, dos seus inegáveis maniqueísmos. Particularmente, com a ambição de assumir um ponto de vista próprio às ciências sociais, temos nos esforçado em tentar apreender o surfe (e os esportes na natureza de modo geral) como um fenômeno social clivado de tensões e de disputas, cujas realidades não seriam nunca dedutíveis a tipificações desse tipo. Nesse sentido, o filme Blue Crush, em si mesmo, enceta uma oportunidade de exercitarmos esse ponto de vista, que assume o paradoxo, a ambivalência e a contradição como elementos estruturais das significações do campo esportivo.

Por tudo, é difícil pensar o surfe em termos dicotômicos, como sendo a expressão de um impulso libertário e contestador, por um lado, ou a manifestação de lógicas de lucro e mercantilização por outro. É pouco produtivo tentar enquadrá-lo como sendo isto ou aquilo, quando na verdade, ele parecer ser isto e aquilo ao mesmo tempo. Não é possível abstrair o desenvolvimento do surfe do contexto social mais geral em que este se deu. O surfe e os surfistas são produtos de uma época marcada pela industrialização de várias esferas sociais [...] Seu impulso no Brasil coincide com o surgimento de uma indústria da cultura e é neste e por este quadro que o esporte se propagou (DIAS, 2009, p. 283).

Não por acaso, toda a estrutura narrativa de Blue Crush oscila sempre entre pólos antagônicos. De um lado, a apologia do surfe feminino; de outro, contraditoriamente, as suas inescapáveis reproduções de estigmas sexistas. Em uma parte, a ambição de uma missão de conscientização sobre o lugar das mulheres no surfe, em outra, a expressão de uma tendência consumista, tradicionalmente identificado à alienação.

Há muito as representações do surfe vêm se debatendo com dilemas desse tipo. Desde quando ideais de profissionalização do esporte passaram a se apresentar de forma mais pronunciada para os surfistas, suas experiências vêm gravitando em torno dessas ambiguidades. Contudo, para além da esfera do consumo, stricto sensu, a publicidade ou a sua comercialização de modo mais geral encerra também possibilidades para a formação de identidades, e o próprio crescimento do surfe feminino o atesta. E isto nada tem de inautêntico ou superficial. Ao mesmo tempo, relações mediadas pela esfera do consumo são obviamente eivadas de motivações pecuniárias, o que tem também suas consequências para as experiências esportivas. De todo modo, importa para uma perspectiva analítica (ou sociológica se quiséssemos), tentar compreender as dinâmicas que tem se desenlaçado nas arenas esportivas do século XXI, admitindo suas complexidades. 


\section{New Endless Summer Dreams: Surf, Women and Others Representations}

ABSTRACT: This article intends to analyze the way that the film Blue Crush (2002) captures, represents and spreads out senses on surf. The premise of this reflection is that the films as themselves catch the practical of sports symbolize, attributing meanings that can be interpreted from that own contends. In this case, three elements of its plot had been taken as analysis axle: i) the way of representation of the woman; ii) the increasing commodification as form of relation with this modality; iii) the realistic-documentary trend of surffilms. They are dimensions that they stage dynamic cultural of this modality, locking up an ambivalence that translates the proper disputes and tensions to any practical cultural.

KEYWORKS: Films; sports and the environment; surfing.

\section{Nuevos sueños de verano sin fin: surf, mujeres y otros modos de representación}

RESUMEN: Este artículo se prepone analizar la manera que la película Blue Crush (2002) captura, representa y hace la difusión de sentidos sobre el surf. El fundamento de la iniciativa es que películas como ésta, cogen el simbolismo del deportes, atribuyendo así significados a ellos que se puedan interpretar desde ellos mismos. En esto en caso, tres elementos hubiera sido tomada para su análisis: i) la representación de la mujer; ii) la comodificación cada vez mayor como forma de si se relacionar con esta modalidad; iii) La tendencia realistadocumental de las películas de surf. Son dimensiones que dramatizan dinámicas culturales en esta modalidad y demarcan una ambivalencia que traduce los conflictos y las tensiones propria a las practicas culturales.

PALABRAS CLAVE: Películas; deportes en la naturaleza; surf.

\section{REFERÊNCIAS}

AMARAL, A.; DIAS, C. Da praia para o mar: motivos à adesão e à prática do surfe. Licere, Belo Horizonte, vol. I I, n. 3, p. I-22, dez. 2008. Disponível em: <http://www.eeffto.ufmg. br/icere/sumario. html?ed=|8>. Acesso em: 19 dez. 2008.

BOOTH, D. Ambiguities in pleasure and discipline: the development of competitive surfing. Journal of Sport History, Los Angeles, v. 22, n. 3, p. 189 - 206, 1995.

Surfing films and videos: adolescent fun, alternative lifestyle, adventure industry. Journal of Sport History, Los Angeles, v. 23, n. 3, p. 313-327, fall 1996.

From bikinis to boardshorts: wahines and the paradoxes of surfing culture. Journal of Sport History, Los Angeles, v. 28, n. I, p. 3-22, spring 2001.

DEBORD, Gui. A sociedade do espetáculo. Rio de Janeiro: Contraponto, 1997.

DIAS, C. Por um programa investigativo para os esportes na natureza. Licere, Belo Horizonte, v. II, n. I, p. I-23, 2008. Disponível em: <http://www.eeffto.ufmg.br/licere/sumario. $h t m l$ ?ed $=\mid 6>$. Acesso em: | 5 abr. 2008. 
n. 4, p. 257-286, 2009.

O surfe e a moderna tradição brasileira. Movimento, Porto Alegre, v. 15,

DIAS, C. ALVES JUNIOR, E. Entre o mar e a montanha: esporte, aventura e natureza no Rio de Janeiro. Niterói: EdUF, 2007.

FLUI R. O surfé a alma do negócio. Disponível em: < http://www.fluir.edicaoeletronica.com. br/noticias/textos/4/em/surf-business/index.html>. Acesso em: 03 dez. 2006.

HENDERSON, M. A shifting line up: men, women and Tracks surfing magazine. Continuum, Oxford, vol. 15, n. 3, p. 319-332, 2001.

MELO, Victor. Esporte e cinema: diálogos. Rio de Janeiro: Aeroplano, 2006.

MELO, Victor; FORTES, Rafael. O surfe no cinema brasileiro. In: DIAS, Cleber; ALVES JUNIOR, Edmundo (Orgs.). Em busca da aventura: múltiplos olhares sobre o esporte, o lazer e a natureza. Rio de Janeiro: EdUFF, 2009, p. I09- 124.

ORLEAM, S. Life's Swell. Disponível em: < http://outside.away.com/outside/destinations/ womanfall I998/maui_surfer_girls_I. html >. Acesso em: 28 dez. 2008.

ORMROD, J. Endless summer (1964): consuming waves and surfing the frontier. Film \& History, Baltimore, vol. 35, n. I, p. 39-5I, fall 2005.

Surf rhetoric in American and British surfing magazines between 1965 and 1976. Sport in History, cidade, vol. 27, n. I, p. 88- 109, march 2007.

SGARBI, L. Surfe para meninas. Isto é, ed. 2048, II de fev. 2009. Disponível em: < http:// www.terra.com.br/istoe/edicoes/2048/surfe-para-meninascom-pranchas-coloridas-efemininas-elas-estao-invadindo-125277-I.htm > . Acesso em: 23 fev 2009.

SLATER, Kelly. A biografia de Kelly Slater: pipe dreams. São Paulo: Gaia, 2004.

STEDMAN, Leanne. From Gidget to Gonad Man: surfers, feminists and postmodernisation. Journal of Sociology, vol. 33, n. I, p. 75-90, march 1997.

Recebido: 09 jun. 2009

Aprovado: 07 ago. 2010

Endereço para correspondência:

Cleber Dias

Rod.Goiânia-Nerópolis, km 12, Campus Samambaia

Caixa Postal I31. Goiânia-GO

CEP 7400 I-970 